\title{
Inhalt / Sommaire
}

Huldrych M. Koelbing, Editorial

\section{Hauptbeitrag}

Axel Hinrich Murken, Grundzüge des deutschen Krankenhauswesens von 1780 bis 1930 unter Berücksichtigung von Schweizer Vorbildern

\section{Mittelalter und frühe Neuzeit}

Peter Bischoff und Peter Speiser, Mittelalterliche Augenheilkunde im Kloster St. Gallen

Hermann Hörger, Krankheit und religiöses Tabu - die Lepra in der mittelalterlich-frühneuzeitlichen Gesellschaft Europas

Vera Waldis, Hospitalisation und Absonderung in Pestzeiten die Schweiz im Vergleich zu Oberitalien

\section{Schweizer Kliniken und Spitäler}

Friedrich Rintelen, Von der Augenheilanstalt zur Universitätsaugenklinik in Basel

Peter Sommer, Die ersten Jahrzehnte des Jenner-Kinderspitals in Bern 85

Adolf M.Fehr, Geschichte des Winterthurer Spitals

Hans H. Walser, Der Weg der Schweizer Psychiatrie ins zwanzigste Jahrhundert

Stefan Loretan, Das Antoniusspital in Brig

Ausland

Ulrich Tröhler, Britische Spitäler und Polikliniken als Heil- und Forschungsstätten 1720-1820

Eduard Seidler, Die Behinderten in Herten

\section{Buchbesprechungen}

Christoph Sachße, Florian Tennstedt, Geschichte der Armenfürsorge in Deutschland. Vom Spätmittelalter bis zum Ersten Weltkrieg (Erwin H. Ackerknecht)

Martin Schwarzbach, Auf den Spuren unserer Naturforscher (Heinz Balmer) 